\title{
Challenges of Management in the Digital Economy
}

\author{
Andrea Bencsik ${ }^{1 *}$
}

${ }^{1}$ Department of Management J. Selye University Komarno, Bratislavska cesta 3322, SK-94501 Slovakia

\begin{abstract}
Industry 4.0, digitalization, and artificial intelligence are the most often-mentioned factors that influence the competitiveness of companies in an innovative future. This study highlights the connections between these areas from the point of view of the management of industrial companies, revealing the challenges from theoretical and practical viewpoints. The most important questions are: On what level are organizations preparing for the digital future? What differences are perceived among the problems of multinational companies (MNCs) and small and medium-sized enterprises (SMEs)? How do managers prepare for change and what changes are they making as they keep the concept of "smart" technologies in mind? This study highlights the results of a qualitative study conducted in 2018-19 using structured deep interviews with 195 higher leaders of MNCs and SMEs (NVivo 12 was used to analyze the answers). The results show that although managers see and feel the urgent challenges, they are not dealing with additional demands beyond technical developments. Handling of human problems is the most serious task; however, managers are continually postponing decisions related to these problems. Overall, even in the largest companies, managers have not arranged anything in preparation for changes or new leadership styles relevant to the digital future.
\end{abstract}

Keywords: Digitalization; Industry 4.0; Leadership; Managerial competencies; SMEs contra multinational companies

\section{Introduction}

The importance of the topic of the Digital Economy is evident in the Google search engine; it can find $823,000,000$ issues in 0.44 seconds. The development of digitalization over the past few decades has led to what is called the 4th Industrial Revolution. This revolution, known as Industry 4.0 (I4.0), was the main issue discussed at the World Economic Forum in Davos, Switzerland, in January 2016. The engineer and economist Klaus Schwab, the Founder and President of the World Economic Forum, declared that this revolution will fundamentally change the way we live. I4.0 aims to combine the strengths of traditional industries with cutting-edge Internet technologies. According to the opinions of experts, this industrial revolution is Internet-based, enabling communication over large networks between people and cyber-physical systems (Brettel et al., 2014; Daneshjo et al., 2017). The scientific literature has been trying to provide an exact definition of the revolution (Gilchrist, 2016) and to determine a list of the components of I4.0 (Iarovyi et al., 2015; Berawi, 2020a, 2020b), such as Internet of Things (IoT), CPS, Smart factory, etc. There are definitions that include reference to artificial 
intelligence (AI), Cyber-Physical Systems, and the Industrial Internet. According to the original German terminology, this digital transformation/revolution is taking place within the value-creating processes of companies (Wang, 2016). In the first few years of the revolution, researchers focused on technical solutions (Industrial Internet Consortium, 2013), whereas nowadays a shift has been detected toward a focus on new business models, innovation, renewable resources, and smart services connected to I4.0. There are several other approaches that do not reflect a unified view on the subject (Liao et al., 2017). At the same time, there are only a few scientific publications that have explicitly dealt with the role, responsibility, and professional competence of leaders. If scholars do mention the importance of this leadership, the issue is discussed within a general context (Črešnar and Jevšenak, 2019). Accepting and managing change is a challenge in itself; however, the new competitors, the new strategies, and the expectations of different generations bring new challenges to leaders, creating an unknown and uncertain environment. As I4.0 focuses primarily on technical development, there is no clear understanding of what knowledge and skills are required from leaders who want to succeed in this new era. According to the recommendations of Bowles (2016), the following competencies and qualities are required: critical thinking, cooperation, creativity, communication skills, curiosity, persistence, initiative, and social sensibility. The study of Batistič et al. (2017) refers to those areas that leaders should think differently about in a digital world: responsibility, results, distribution of information, objectives, assessments, mistakes and conflicts, change, and innovation.

The study by PwC, "Industry 4.0: Building Digital Enterprise," points out that the technology required to implement I4.0 is ready; the problem is the missing digital culture, vision and training, and lack of professionals (PwC, 2016). We felt it was important to fill the current gap in the scientific literature by conducting research with a focus on the professional competence, knowledge, future visions, and expectations of leaders (first gap). The second gap identified in the literature is the lack of methodologies to overcome the practical issues and challenges that managers have to face in the transformation process. The third gap in the literature is linked to people. Employees and management, in general, are one of the major issues for I4.0, because new skills, behavior, and attitudes are required by both employees and leaders. To prepare for the transformation, it is not only the operators and technical systems that have to be involved, but the managers must also become acquainted with the new requirements, new ideas, tools, business models, and new relationships with customers and partners. This is called Leadership 4.0. Finally, the fourth gap is that the above-mentioned research focuses on Western countries only and not on Middle-East-European countries.

The aim of this research is to access and engage with the leaders of companies (both in large and the SME sector) to determine what they need to be prepared for, where they are currently in terms of knowledge and assessment of their leadership work, and how prepared they are for the upcoming changes. The research questions are formulated as follows.

RQ1: To what degree are organizations prepared for the digital future? RQ2: What is the biggest challenge for management beyond technical changes? RQ3: What are the differences in how problems are perceived by multinational companies and SMEs? RQ4: Are there generational problems connected to digitalization, and if so, how do managers handle them? RQ5: What are the changes required and how are managers preparing for them, keeping the concept of "smart" in mind?

\section{Methods}

The present study intends to compare the research results of three European (among them two Middle-East-European) countries based on the theoretical background and the 
practical research results. In a qualitative survey, interviews were conducted with the representatives of top and middle management of multinational companies and SMEs in 2018-19. Two neighboring Middle-East-European countries (Hungary and Slovakia) participated in the research. These countries share a similar economic and social history, but have different cultural backgrounds. The third country (Germany) was selected because Germany is Europe's largest economy and the second-most populous nation (after Russia). Germany is a key member of the continent's economic, political, and defense organizations. The phenomenon on which the strategy I4.0 was built was first recognized in Germany. Germany is present as the most important European investor in the two mentioned countries and is the economic player with the highest score of added value. Because a significant percentage of exports to Germany is produced by subsidiaries of German companies in both countries, the investments of parent companies in I4.0 will significantly determine the spread of technologies in Hungary and Slovakia.

\subsection{Size of Dataset}

In-depth interviews with the leaders of SMEs and multinational companies (Hungary, Slovakia, Germany) form the basis of this analysis. Based on the above reasons (dominant presence of Germany in both countries), local companies and subsidiaries of German multinationals participated in the survey, in addition to SMEs that act as suppliers to these large companies. This sampling concept provides an opportunity to ensure the same basis for comparison during the analysis. The number and distribution of companies included in the sample was defined according to the rate of added value (SME/Multi) typical of each country (European Commission, 2016). The companies involved in the examination were selected at random. The sample provides representative results for the countries regarding the issue under examination. The characteristics of SMEs are: max. 250 employees, turnover of less than 50 million Euros, and a total balance sheet of max. 43 million Euros. Table 1 presents the number of leaders of the surveyed companies.

Table 1 Companies involved in the survey

\begin{tabular}{lcccc}
\hline \multicolumn{1}{c}{ Characteristics/countries } & Germany & Hungary & Slovakia & $\Sigma$ \\
\hline Number of interviews conducted & 75 & 60 & 60 & 195 \\
$\begin{array}{l}\text { Number of multinational } \\
\text { companies/subsidiaries }\end{array}$ & 33 & 27 & 24 & 84 \\
Number of SMEs (suppliers/partners) & 42 & 33 & 36 & 111 \\
\hline
\end{tabular}

\subsection{Research Method}

The researcher applied qualitative research techniques during structured interviews with the leaders. The interviews were in-person and lasted at least an hour. The leaders were selected on the basis of conscious consideration; in the case of multinational companies, they were chosen from middle and senior management levels and from different areas of expertise; in the case of SMEs, they were selected from the senior management level. The questions fell into four main groups, each with 4-8 questions.

- The Effects of Digitalization and I4.0: How do managers perceive the challenges of the future in their private and work lives?

- New Demands, Intergenerational Management: If there are differences among generations, how can managers handle them? (motivation, teamwork)

- Values of the Future, Preparations: Requirements of training at a different level of the hierarchy, change management in business, and leadership style.

- Vision and Expectations: Expectations, fears, individual and organizational visions. 


\subsection{Assessment Methodology}

In consideration of the interview technique (qualitative research technique), the method of content analysis was used to evaluate the information received (Krippendorf, 1995). In addition to notes made during the interviews, a transcript was made of the conversations. A content analysis was conducted with the help of fast coding based on the logic of the interview plan. The NVivo 12 program was chosen to identify the most frequently used terms in order to determine their frequency, compare the frequency of terms on national and organizational levels, and provide a visualization of the results.

\subsection{The Process of Evaluating the Results}

The evaluation followed the logical course of content analysis. During the phase of preparation, the texts of the recorded interviews were corrected and uploaded to the computer system. There were three further phases undertaken before the results were interpreted.

- Encoding: The words and expressions used in the interview were a target for analysis.

- Analysis: The frequency of words, characteristic expressions, and their appearance in the text, their number in the 1-1 category, and the appearance of multiple codes were examined. Each code symbolizes some meaning, but the occurrence of a combination of two to three codes results in a "meaning surplus," which was not exactly in the original text, but which provides a possibility for further conclusions. It was also important to look at the missing phrases, as these deficiencies may have further relevance.

- Interpretation: The tendency-like occurrence of phrases in the text is attention-grabbing and can serve as a basis for further conclusions.

\section{Results and Discussion}

\subsection{Analysis}

The prepared documents were separated according to interview questions/question groups. The other aspects of categorization were size of the corporation and national affiliation.

Some characteristic results obtained during the research will be highlighted in comparison with earlier research results. As far as the typical words are concerned, the first five most frequently used expressions will be displayed ("Five words method").

\subsection{Results of the Analysis}

The analysis will be based on interview questions.

The first category, "Effects of Digitalization and I4.0," presents the most commonly used expressions based on the analysis of the complete survey. The responses of leaders reflect how important they feel the urgent tasks and changes in their private and professional lives are. The question is: What comes to mind first on hearing the expression "Industry 4.0"?

Based on the analysis of the complete sample, the most frequently used expressions can be seen in Table 2 .

Table 2 The most frequently used expression in the first question group

\begin{tabular}{cccccc}
\hline Altogether SME & $\%$ & Altogether multi & $\%$ & $\begin{array}{c}\text { Altogether } \\
\text { (SME + multi) }\end{array}$ & Percentage \% \\
\hline Online & 95 & Important & 93 & Online & 89 \\
Communication & 82 & Tool & 80 & Important & 77 \\
People & 75 & Work & 72 & Communication & 67 \\
Tool & 50 & Personal & 68 & Tool & 65 \\
Relationship & 64 & Digitalization & 61 & People & 56 \\
\hline
\end{tabular}


The wordlist reflects general thinking and contains the most expressive words. The term "online" was ranked first in the analysis (not surprising), but as the sample is divided between multinationals and SMEs, it is clear that the expressions were mainly mentioned by the managers of SMEs. The term "important" was a favorite expression of leaders in multinational companies, which was accompanied by the expressions of "preparation," "change," "IT," and "communication." "Communication," which is the third most commonly used expression, was frequently used by the leaders of SMEs. "Communication" together with the expression of "personal" shows a frequent occurrence with multinational companies. The expression "tool" appears in both of the samples of multinationals and SMEs; only the order is different. Even more meaning is added to this expression if we examine the joined occurrences. In this case, "electronic," "IT," "smart," "technology," and "mobile" are associated with the expression "tool," which will dominantly characterize a general way of thinking. The term "people" is also included among the most frequently used expressions of the analysis, since the human aspect cannot be ignored. At the same time, no expressions are found to forecast the future vision i.e. "artificial intelligence," "digital strategy," "change," "innovation," etc. Further analysis is required for a detailed overview. The results based on the analysis of the nations are presented in Table 3.

Compared to the summarized results of SMEs, the German and Slovak samples show the occurrence of 3-3 identical terms (though they are different), while the Hungarian sample shows two matches. These two are the most important terms of the other two nations as well. The comparison shows a single common term used in all three cases. This term is "online." Apart from this term, there is a single case in thinking of nations that shows similarity, which is shown in German-Hungarian comparison in case of the term "tool." As the terms "communication" and "relationship" occur in the Slovak and the summary sample, this can be said to be very dominant in their thinking. The same applies in the case of the term "people" in the German sample.

Table 3 The most important terms based on the evaluation of nations

\begin{tabular}{|c|c|c|c|c|}
\hline \multicolumn{3}{|c|}{ SMEs } & \multirow{2}{*}{ Altogether SMEs } & \multirow{2}{*}{$\begin{array}{c}\text { Percentage } \\
(\%)\end{array}$} \\
\hline Hungarian \% & Slovak \% & German \% & & \\
\hline Tools 94 & Generation 94 & People 96 & Online & 92 \\
\hline Important 92 & Communication 93 & Innovation 95 & Communication & 75 \\
\hline Online 91 & Online 91 & Online 94 & People & 70 \\
\hline Personal 84 & Relationship 88 & Tools 56 & Tool & 68 \\
\hline Work 76 & Information 84 & Internet 55 & Relationship & 63 \\
\hline \multicolumn{3}{|c|}{ Multinationals } & \multirow{2}{*}{ Altogether multi } & \multirow{2}{*}{$\begin{array}{c}\text { Percentage } \\
(\%)\end{array}$} \\
\hline Hungarian $\%$ & Slovak \% & German \% & & \\
\hline Important 82 & Continuous 81 & Important 82 & Important & 79 \\
\hline Online 79 & Important 73 & Person 80 & Tools & 70 \\
\hline Tools 78 & Young 71 & Digitalization 74 & Work & 66 \\
\hline Communication 75 & Fast 67 & Tools 72 & Person & 64 \\
\hline Person 72 & Development 62 & Continuous 64 & Digitalization & 61 \\
\hline
\end{tabular}

Summarizing the results of the analysis, it is notable that the leaders experienced the challenges and the use of online equipment through the communication requirements. The need for change was expressed, but the process to connect digital strategy, innovation, and AI still lags behind. Most of the leaders of the Hungarian multinational companies said that they only talk about I4.0, but do not experience it in everyday life. However, they have agreed to be faster, more creative, and innovative to maintain competitiveness, but in the 
current system, which has strictly regulated processes (mainly characteristic of German companies), this is complicated.

As the diverse vocabulary of definitions in literature indicates, thinking about I4.0 is not on the same level. The most frequently used terms in the definitions are smart, system, process, virtual, flexible, development, cloud, IoT, computing, AI, Big Data, techniques, innovation, people, and technology (Lasi et al., 2014; Iarovyi et al., 2015; Götz and Jankowska, 2017).

Comparing the most commonly used terms in the survey, only three terms are the same: tools, techniques, digitalization, practice, effectiveness, development, IT tools, continuously, process, information, and system. This result can be important to decide on how to develop and influence leadership thinking, training, and development.

Comparing the results of our research with previous studies, the situation seems to be similar worldwide. There are countries at the forefront of preparing for the future and accepting changes, such as Japan or Switzerland in Europe, and the gaps and lacks are almost identical (Gentner, 2016).

Fujitsu (2017) conducted a survey among the business executives of 15 countries worldwide with the main objective of discovering the attitudes of business executives toward digital transformation. Based on the results, $89 \%$ of business activities currently involve planning, testing, or introducing digital initiatives, using technologies such as AI or the IoT (Computerworld, 2017).

\subsubsection{New demands, intergenerational management}

The respondents were asked to judge their organization in terms of generational differences, whether it is an existing phenomenon in their organization, and how they deal with the problem, including which motivational tools they use to treat it effectively. Based on the general opinion of the respondents, generational differences are always present, but there are no serious problems. The employees both want to and can work together; teamwork is preferred, and they can help each other. The leaders had more difficulties with motivational tools; however, they did not feel this was a difficult task for them.

The results of both the nations and size of businesses show similar terminology used: "young," "generations," "team," "cooperation." Further expressions e.g. "there is no problem," "teamwork," "cooperation of younger and older," and "there is no generation gap" show that cooperation between generations is not a serious problem. The term "problem" is mentioned in connection with motivation, which means that this issue should be addressed.

\subsubsection{Values of the future, preparations}

Most of the questions deal with "training" from the perspective of both employees and leaders. The opinions are partially different; for staff training, the managers of Hungarian and German SMEs and multinationals had a similar opinion, while managers of Slovak SMEs found it less important. As far as self-training is concerned, the leaders of Hungarian and German companies and the leaders of Slovak multinationals found development to be less important. Only the leaders of Slovak SMEs evaluated their self-training higher than the training of their employees. The managers of Hungarian SMEs noted self-training as the most important issue, whereas for Slovak multinationals, this was the least important factor.

The above results are in line with the earlier research that shows a positive attitude of employees toward digitalization; only the Hungarians are lagging behind compared to other countries (Randstad, 2019).

The changes in relationships were evaluated highly by the respondents. The managers of Hungarian SMEs gave the highest evaluation to changes, while managers of Slovak SMEs 
felt it less. The results of the qualitative analysis show that changes were mainly associated with the expressions of "impersonalization" and "easier." According to the context, this means that the changes are mainly characterized by impersonalization; however, making and maintaining contacts have become easier and simpler with the use of digital tools. Many have emphasized that the increased and heavy workload results in stress, puts more pressure on leaders, and at the same time requires a higher level of flexibility and a new approach. They have also emphasized that it is not enough to follow technological innovations; cultivating personal relationships is even more important. The survey also explored which values are important to preserve in the new era. The most frequently reported terms are shown in Table 4.

Table 4 Key values in the digital age

\begin{tabular}{|c|c|c|c|c|c|}
\hline \multicolumn{2}{|c|}{ Hungarian } & \multicolumn{2}{|c|}{ Slovak } & \multicolumn{2}{|c|}{ German } \\
\hline SME \% & Multi \% & SME \% & Multi \% & SME \% & Multi \% \\
\hline People 88 & $\begin{array}{l}\text { Relation } \\
\text { ships } 84\end{array}$ & $\begin{array}{l}\text { Relationships } \\
87\end{array}$ & People 92 & People 94 & People 91 \\
\hline Family 83 & People 82 & People 84 & Reliability 88 & Efficiency 89 & Digitalization 86 \\
\hline Speed 78 & Reaction 78 & Friend 81 & Business 84 & $\begin{array}{l}\text { Relation } \\
\text { ships } 84\end{array}$ & Task 84 \\
\hline Internet 72 & Personal 74 & Family 76 & Objective 80 & System 79 & Thinking 78 \\
\hline $\begin{array}{l}\text { Communicati } \\
\text { on } 65\end{array}$ & $\begin{array}{l}\text { Knowledge } \\
68\end{array}$ & $\begin{array}{l}\text { Each other } \\
68\end{array}$ & Commitment 72 & Family 74 & Efficiency 74 \\
\hline
\end{tabular}

As presented in the table above, the most frequently used term "people" (see percentages) and the terms related to that e.g. "personal," "each other," "relationships," "family," and "friend" appear on the list of the nations studied in this survey. This is remarkable, since in the era of technology, machines, and AI, everybody can feel the importance of human relationships. There are a few expressions related to business life, e.g. "speed," "reaction," "efficiency," "task," "thinking," "business," "knowledge," but their importance is low. In reviewing the opinions of respondents, it became evident that the German multinational companies emphasized the importance of fundamental human values, such as respect, appreciation, honesty, and tolerance. They also emphasized the importance of know-how, engineering thinking, and the importance of motivated individuals.

The influence of the digital age on leadership style and the effect of changes were also included among the questions. The results are astonishing. Only $25 \%$ of the respondents expressed the strength of the effect. This result is surprising, because the earlier questions show that the leaders are aware of the new requirements and preparation for them is in progress, but their impact is not enough for the leaders to feel that change is essential for them. This fact is supported by a low evaluation for leadership training.

\subsubsection{Expectations and future}

In the final parts of the interviews, the leaders were asked to address the challenges they face regarding the new industrial revolution and provide a short and mid-term future vision of the company they work for. Most of the leaders of the multinational companies see a problem with inertia of companies (primarily due to the size of the company, combined with a strong insistence on the controlled processes of the German company culture) and the fact that the current technological progress will not be enough to remain successful. The evolution of technology precedes the process of human evolution, and the profile of companies might also change. A positive future is forecasted if time is spent on preparation, 
training, developing a different attitude, and introducing a new form of creativity. Some of the answers about the challenges and visions are listed below.

\subsubsection{Challenge}

The leaders of the Hungarian multinationals: "They cannot keep up with the rapid change." "It is difficult to hire employees with high technological skills." "The technological knowledge is low; there is a slow response to change." "There is not enough experienced and well-trained staff." "It is difficult to adapt to new technologies," "High satisfaction level of consumer need."

The leaders of Slovak SMEs: "I do not feel the challenge." "The use of smart devices/ getting to know Facebook and Google business." "The online form of supplier orders is a challenge." "I had to master the use of new devices." "Artificial intelligence." "There is no challenge."

\subsubsection{Vision}

Slovak multinationals: "The use of artificial intelligence, robotization," "The spread of intelligent machines; decrease of human labor."

German SMEs: "Growth, change in the market situation." "Increasing the number of customers, increasing profit." "New products, continuous expansion." "Operating new organizational structure."

German multinationals: "Innovation, development, and increasing quality," "Further international expansion," "Increasing investments into digital technology," "Total robotization, continuous development," "Automated work processes, electric cars."

Reading and listening to the future plans, it is evident that something is missing-human presence and roles are not emphasized.

Based on the analysis, the answers to the research questions are summarized below.

\section{RQ1: To what degree are organizations prepared for the digital future?}

The leaders of the surveyed companies are aware of the inevitable changes in this new era, but they find it difficult to formulate the concept of I4.0. They can feel technological development and take it as a natural part of the development process. Their most frequently quoted terms describe their knowledge in the field. Innovation, AI, cloud-based technology, and the vision of a smart future are discussed, but aspects of leadership thinking are missing. This deficit will also define the orientation of leadership training. We have a mixed picture about training as a tool of preparation.

\section{RQ2: What is the biggest challenge for management beyond technical changes?}

Besides technical changes, the major problems are expertise, human resources, a lack of human capacity, and difficulty retaining young staff; these problems are not always linked to technical change. SMEs?

RQ3: What differences in how problems are perceived by multinational companies and

Quite strong differences in thinking can be detected between SMEs and multinationals. The difference in thinking of leaders was identified following the analysis of terms they use the most frequently. While multinationals consider the tools of digitalization and personal meetings the most important, the presence of human factors, online presence, communication, and relationships have more importance for SMEs. Comparing the results of the nation-based comparison, the human aspect is particularly emphasized in German thinking, whereas generational problems are an issue in Slovakia, and ensuring tools is a challenge for Hungarians. The values considered to be important by leaders show a close relationship to their vision about their leadership style. Half of the respondents think that the forthcoming changes will have no influence on their leadership style. Only a quarter of 
the respondents think they have to adjust their current style of company management. The managers of SMEs, especially the Hungarians, appreciated employee training, while the Slovak multinationals found self-training to be the least important. AI and related training have attracted the enthusiasm of the respondents, but their importance is less emphasized in this study. Managerial flexibility and thinking in terms of new business models were more characteristic for the SME sector. The managers of SMEs have more impact on business operations and determining work time than the leaders of multinational companies.

RQ4: Are there generational problems connected to digitalization, and if so, how do managers handle them?

Generational differences do not seem to be a problem. All of the leaders mentioned the existence of generational differences, but they felt these were being handled well. Rather positive associations were mentioned, such as "cooperation," "mutual help," "support," "learning from each other," and "teamwork." Neither the SMEs nor multinationals have found a good solution for retaining young employees. Some practices have already been introduced by SMEs (flexitime, home office, smart devices), but none of them have proved successful.

RQ5: What are the changes required and how are managers preparing for them, keeping the concept of "smart" in mind?

The managers' assessment of the situation, as well as their future vision, is rather sad. Although they feel a new era is close, they do not have a strong determination to change or think proactively. Many of the managers described feeling no challenge at all and noted that they do not feel they have to change anything personally (this was mainly declared by the leaders of Slovak SMEs). Doubts were expressed especially by German and Hungarian multinationals how serious the change is. Only a small number of the respondents felt that technological change, AI, and robotization present a challenge. The majority of SME leaders noted that they think about expansion, growth, new market share, and business success (friendship and family are also in focus), whereas multinational leaders emphasized the role of personal relationships, communication, knowledge, and thinking. This is the field where the most differences can be detected between the German leaders of multinational companies and the rest of the leaders. The German leaders have the boldest ideas about the future regarding investments, digitalization, international relations and expansion, $\mathrm{AI}$, and the field of robotization.

\section{Conclusions}

All of the above-mentioned research and the results from this clarify that the world is preparing for the challenges of the new industrial revolution. Still, the deficiencies of organizational culture are the main obstacle to achieving corporate success.

The results of our research prove that, in theory, managers are aware of the urgency facing them, but they are not making the necessary preparations. They are not dealing with the tasks that would mean re-evaluating their managerial activities, primarily in terms of soft categories (motivation, managing integrational conflicts, competence development, training, change in leadership style, shaping of culture, etc.).

Significance of the Research

The aim of this study was to make a comparison that has not yet been the subject of research in the literature. In Europe, the influence of the German economy is indisputable. We wanted to show the emergence of this dominance in relation to two other nations, where German ownership is the number one presence in terms of investment and value- 
added production per country. Researching the impact of this economic dominance and the enforcement of its decisions from the viewpoint of I4.0 and digitalization, beyond the theoretical approach to results, provides additional ideas for practical life in favor of development. There are significant differences between this study and previous research, where most of the methods used have been questionnaire surveys, and where the countries involved are often the USA, Indonesia, and Germany. No comparative analyses have been found in the literature for the countries we have examined. Similar questions related to the interpretation of digitalization and I4.0 can be read in previous studies, but the main focus, purpose, and questions are different. A particularly interesting and dominant difference from previous studies is the comparison of leadership vision and future values across the three countries.

\section{Acknowledgments}

The publication of this article was supported by the Pallas Athene Foundations.

\section{References}

Batistič, S., Černe, M., Vogel, B., 2017. Just How Multi-Level is Leadership Research? A Document Co-Citation Analysis 1980-2013 on Leadership Constructs and Outcomes. The Leadership Quarterly, Volume 28(1), pp. 86-103

Berawi, M.A., 2020a. Managing Artificial Intelligence Technology for Added Value. International Journal of Technology, Volume 11(1), pp. 1-4

Berawi, M.A., 2020b. Nature 5.0: The Role of Digital Technologies in the Circular Economy. International Journal of Technology, Volume 11(4), pp. 652-655

Bowles, M. 2016. Leadership in the Digital Economy (Industry 4.0). Available Online at https://www.researchgate.net/publication/308405209_Leadership_in_the_Digital_Ec onomy_Industry_40, Accessed on January 17, 2019

Brettel, M., Friederichsen, N., Keller, M., Rosenberg, M., 2014. How Virtualization, Decentralization and Network. Building Change the Manufacturing Landscape: An Industry 4.0 Perspective. International Journal of Information and Communication Engineering, Volume 8, pp. 37-44

Computerworld, 2017. Ösztönzi az üzleti növekedést a digitális átalakulás (Stimulate Business Growth With Digital Transformation) . Available Online at https://computerworld.hu/uzlet/osztonzi-az-uzleti-novekedest-a-digitalisatalakulas-228156.html, Accessed on January 17, 2019

Črešnar, R., Jevšenak, S., 2019. The Millennials' Effect: How Can Their Personal Values Shape the Future Business Environment of Industry 4.0? Naše Gospodarstvo/Our Economy, Volume 65(1), pp. 57-65

Daneshjo, N., Majerník, M., Danishjoo, E., 2017. More Exact Approaches to Modernization and Renewal of the Manufacturing Base. TEM Journal, Volume 6, pp. 445-449

European Commission, 2016. SBA Fact Sheet (Germany, Hungary, Slovakia). Available Online at https://ec.europa.eu/docsroom/documents/22382/.../15/.../native, Accessed on January 24, 2019

Fujitsu, 2017. Global Digital Transformation Survey Report. Available Online at https://www.fujitsu.com/downloads/GLOBAL/vision/2017/downloadcenter/FTSV2017_Survey_EN-1.pdf, Accessed on January 22, 2020

Gentner, S., 2016. Industry 4.0: Reality, Future or just Science Fiction? How to Convince Today's Management to Invest in Tomorrow's Future! Successful Strategies for 
Industry 4.0 and Manufacturing IT. CHIMIA International Journal for Chemistry, Volume 9, pp. 628-633

Gilchrist, A., 2016. Industry 4.0: The Industrial Internet of Things. New York: Apress

Götz, M., Jankowska, B., 2017. Clusters and Industry 4.0 - Do They Fit Together? European Planning Studies, Volume 25, pp. 1633-1653

Iarovyi, I.J., Lastra, L.M., Haber, R., Del Toro, R., 2015. From Artificial Cognitive Systems and Open Architectures to Cognitive Manufacturing Systems. In: Proceeding of IEEE International Conference on Industrial Informatics, INDIN, pp. 1225-1232

Industrial Internet Consortium, 2013. Industrial Internet Consortium, 2013: Fact Sheet. Available Online at http://www.iiconsortium.org/docs/IIC_FACT_SHEET.pdf (3.12.2014), accessed on November 12, 2018

Krippendorf, K., 1995. A tartalomelemzés módszertanának alapjai (Fundamentals OfContent Analysis Methodology). Budapest: Balassi

Lasi, H., Fettke, P., Feld, T., Hoffmann, M., 2014. Industry 4.0. Business \& Information Systems Engineering, Volume 6, pp. 239-242

Liao, Y., Deschamps, F., Loures, E.F.R., Ramos, L.F.P., 2017. Past, Present and Future of Industry 4.0 - A Systematic Literature Review and Research Agenda Proposal. International Journal of Production Research, Volume 55, pp. 3609-3629

PwC 2016. Industry 4.0: Building the Digital Enterprise, 2016 Global Industry 4.0 Survey, What we mean by Industry 4.0 / Survey key findings / Blueprint for digital success 2016. Available Online at www.pwc.com/industry40, Accessed on October 23, 2018

Randstad, 2019. Munkahelyi digitalizáció és STEM - a friss Randstad Workmonitor kutatás tanulságai (Workplace Digitization and STEM - Lessons from Recent Randstad Workmonitor Research). Available Online at https://www.randstad.hu/allaskeresoknek/karrier-tippek/karrier/munkahelyidigitalizacio-es-stem-a-friss-randstad-workmonitor-kutatas-tanulsagai/, Accessed on November 2, 2020

Wang, K., 2016. Intelligent Predictive Maintenance (IPdM) system - Industry 4.0 scenario. WIT Transactions on Engineering Sciences, Volume 113, pp. 259-268 